\title{
SIMULASI PENGARUH UKURAN PIEZOELEKTRIK DAN KEBISINGAN KERETA REL DIESEL TERHADAP TEGANGAN DENGAN MENGGUNAKAN ANSYS
}

\author{
Ilham Satrio Utomo ${ }^{1}$, ilham.satrio@ppi.ac.id \\ Henry Widya Prasetya ${ }^{2}$, henry@ppi.ac.id \\ Moch. Aziz Kurniawan ${ }^{3}$, aziz@pktj.ac.id \\ ${ }^{1,2}$ Teknologi Mekanika Perkeretaapian, ${ }^{3}$ Teknologi Otomotif \\ ${ }^{1,2}$ Politeknik Perkeretaapian Indonesia Madiun, ${ }^{3}$ Politeknik Keselamatan Transportasi Jalan Tegal
}

\begin{abstract}
ABSTRAK
Tujuan dari penelitian ini adalah untuk mengetahui pengaruh variasi ukuran piezoelektrik dan kebisingan lokomotif kereta terhadap tegangan yang dihasilkan dengan menggunakan ANSYS. Variasi Ukuran Pezoelektrik yang digunakan adalah $1 \times 1,3 \times 3,5 \times 5(\mathrm{~cm})$. Sedangkan untuk variasi kebisingan yang digunakan adalah 93, 96, 98, $100(\mathrm{~dB})$. Metode yang digunakan adalah dengan metode numerik; dalam hal ini Finite Element Analysis (FEA) dengan bantuan program struktural Statis ANSYS. Hasil penelitian menunjukkan dengan menggunakan piezoelektrik $5 \times 5 \mathrm{~cm}$ dan pada kebisingan $100 \mathrm{~dB}$ dihasilkan tegangan maksimal $158,12 \mathrm{mV}$.
\end{abstract}

Kata Kunci : Kebisingan, Tekanan, Piezoelektrik, Lokomotif, Kereta, tegangan.

\section{ABSTRACT}

The purpose of this study was to determine the effect of variations in electrical piezo size and train locomotive noise to the voltage generated using ANSYS. Pezoelectric Size variations used are 1x1, 3x3, 5x5 (cm). As for the noise variations used are 93, 96, 98, $100(\mathrm{~dB})$. The method used is the numerical method; in this case Finite Element Analysis (FEA) with the help of ANSYS Static structural program. The results showed that using piezoelectric $5 \times 5 \mathrm{~cm}$ and at $100 \mathrm{~dB}$ noise produced a maximum voltage of $158.12 \mathrm{mV}$.

Keywords: Noise, Pressure, Piezoelectric, Locomotive, Train, Voltage.

\section{LATAR BELAKANG}

Kereta api saat ini dianggap salah satu moda transportasi paling signifikan karena volume penumpang yang besar dan ketepatan waktu yang cukup baik. Permintaan penumpang kereta api mengalami peningatan dari tahun ke tahun. Peningkatan kebutuhan kereta untuk moda transportasi berbanding lurus dengan peningkatan energy. Saat ini, sektor transportrasi memiliki peran besar dalam konsumsi bahan bakar fosil yakni sekitar 20\% [1]. Oleh karena itu kebutuhan akan energy terbarukan pada kereta menjadi menarik untuk di bahas.

Hukum kekekalan energi menyatakan bahwa "energy tidak dapat diciptakan dan dimusnahkan", Energi hanya berubah bentuk. Dengan hukum tersebut, pada dasarnya energy suara dapat berubah bentuk menjadi energy listrik yang dapat dimanfaatkan untuk kebutuhan pada kereta api. Hal tersebut diharapkan dapat mengurangi beban generator, yang berakibat menurunnya konsumsi bahan bakar. Kereta rel diesel elektrik pada pengukuran kebisingan menghasilkan kebisingan diantaranya pada knalpot engine, engine, generator, kipas pendingin radiator, kipas rem dinamis, blower, motor traksi, dan kompresor penampung debu. [2].

Banyak upaya penelitian telah dikhususkan untuk teknologi yang berfokus pada pemanenan energi alternatif atau konversi energi. Zhang et al. merancang system pemanenan energi kinetik untuk memanen daya yang terbuang dari kendaraan yang melewati terowongan jalan [3]. Untuk digunakan dalam kendaraan listrik jarak jauh, Zhang et al. membuat sebuah peredam kejut untuk mengumpulkan energi suspensi yang terbuang dari kendaraan yang bergerak secara dinamis 
[4]. Teknologi pemanenan energy menjadi alternative baru untuk memenuhi kebutuhan energy [5]. Zhang et al. mengembangkan desain pemanenan energi elektro-magnetik portabel yang mengubah getaran jalur kereta api menjadi listrik melalui transmisi mekanis, dan pemanen energi yang diteliti terbukti efektif dengan menghasilkan efisiensi 55,5\% [6]. Guan et al. meneliti sistem piezoelektrik untuk memanen energi dari gerakan rotasi, seperti generator yang terintegrasi ke permukaan. Selama rotasi pemanen energi, deformasi berulang, elemen piezoelektrik akan dirubah menjadi listrik, dan energi output yang dihasilkan 83,5-825 $\mu \mathrm{W}$ diperoleh pada frekuensi rotasi 7-13,5 Hz. [7].

Meskipun berbagai teknologi pemanenan sumber daya energi telah ditelitii secara luas, ada energi yang terbengkalai dan terbuang di sekitar kita. Sebagai contoh, energi akustik adalah sumber energi yang signifikan yang dihasilkan terus-menerus tetapi tidak digunakan [8]. Dengan kebisingan yang dihasilkan oleh lokomotif penelitian ini meneliti pemanenan energy suara yang dihasilkan oleh lokomotif sebagai penggerak kereta.

\section{METODE PENELITIAN}

\subsection{Data Kebisingan}

Data kebisingan kereta pada lokomotif didapat dari lokomotif Prambanan Expres (Paramex). Pada penelitian Fayyadl [9] didapat kebisingan pada lokomotif pada engine room adalah 95,4 dB-99,2 dB. Berdasar data sekunder penelitian tersebut maka pada penelitian ini menggunakan rentang variasi 93, 96, 98, $100(\mathrm{~dB})$. Dari kebisingan tersebut kemudian di konversi menjadi tekanan $(\mathrm{Pa})$ dengan menggunakan formulasi. Formulasi yang digunakan adalah dengan menggunakan formula di bawah ini

$$
L_{p}=10 \log _{10} \frac{P_{r m s}^{2}}{P_{o}^{2}}
$$

Dari Formula rumus tersebut maka didapatkan hasil pada tabel 1

Tabel 1 Konversi Tingkat Kebisingan (dB) ke Tingkat Tekanan Bunyi (Pa)

\begin{tabular}{lcc}
\hline No & $\begin{array}{c}\text { Tingkat } \\
\text { Kebisingan }(\mathbf{d B})\end{array}$ & $\begin{array}{c}\text { Tingkat } \\
\text { Tekanan Bunyi } \\
(\mathbf{P a})\end{array}$ \\
\hline $\mathbf{1}$ & 93 & 0.89 \\
\hline $\mathbf{2}$ & 96 & 1.26 \\
\hline $\mathbf{3}$ & 98 & 1.58 \\
\hline $\mathbf{4}$ & 100 & 2 \\
\hline
\end{tabular}

Selain menggunakan variasi dengan kebisingan penelitian ini juga menggunakan variasi ukuran piezoelektrik. Variasi ukuran piezoelektrik ini digunakan untuk mengetahui karakteristik piezoelektrik pada setiap ukuran. Selain hal tersebut juga untuk mengetahui besaran voltase setiap variasi yang digunakan tersebut. Variasi ukuran Piezoelektrik pada penelitian ini adalah 1x1 (cm), 3x3 (cm), dan 5x5 (cm).

Berdasarkan rancangan variasi tersebut maka penelitian ini akan diselesaikan dengan menggunakan simulasi ANSYS. Secara umum proses simulasi CFD dibagi menjadi 3 yaitu Pre Prosesing, Prosesing, dan Pos-Processing.

\subsection{Geometri}

Geometri yang digunakan dalam simulasi ini dimodelkan sebagai domain padat kontinu, terdiri dari 3 bagian yang terpisah, tetapi dihubungkan oleh daerah kontaknya untuk mentransfer data (tegangan, defleksi, tegangan, dll.). Setiap bagian didefinisikan oleh bahan yang berbeda, ada (1) Steel atau Brass, (2) keramik dan (3) karbon aktif. Ini adalah model-model berikut 


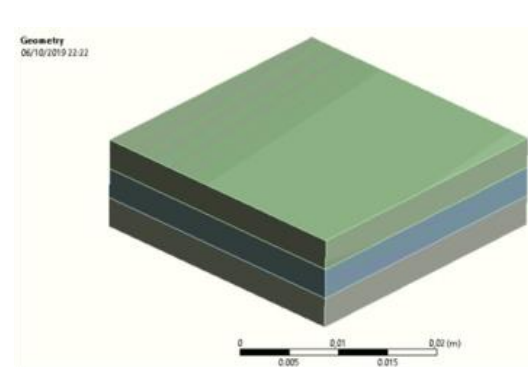

(a)

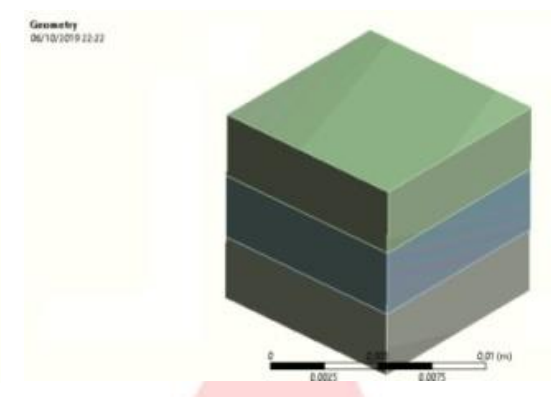

(b)

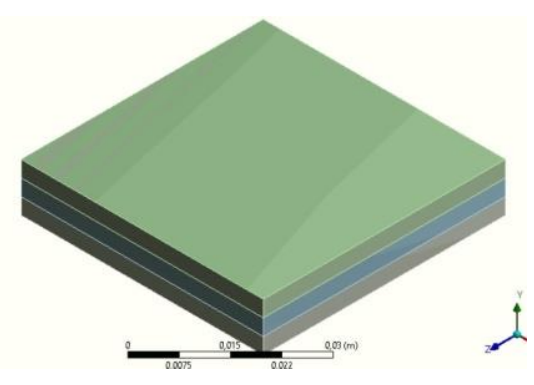

(c)

Gambar 1 Geometri Piezoelektrik (a) 1x1 (b) 3x3 (c) 5x5 (cm)

\subsection{Meshing}

Meshing atau diskretisasi adalah proses mengubah domain padat kontinu menjadi domain komputasi diskrit, sehingga solusinya dapat diselesaikan dengan metode numerik; dalam hal ini Finite Element Analysis (FEA) dengan bantuan program struktural Statis ANSYS.

Pengaturan mesh yang digunakan adalah (1) body sizing: untuk memastikan ukuran elemen minimum

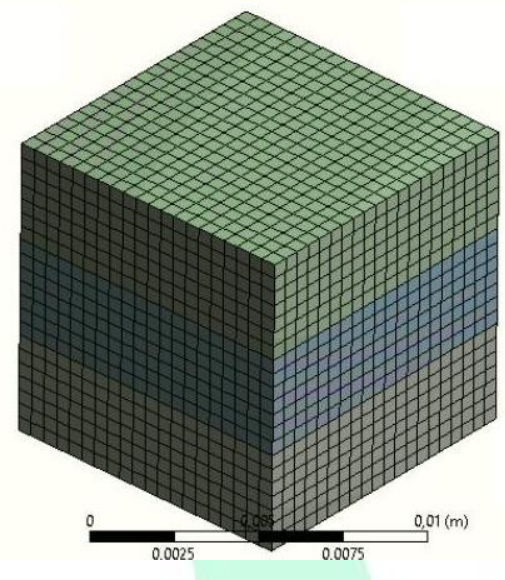

(a)

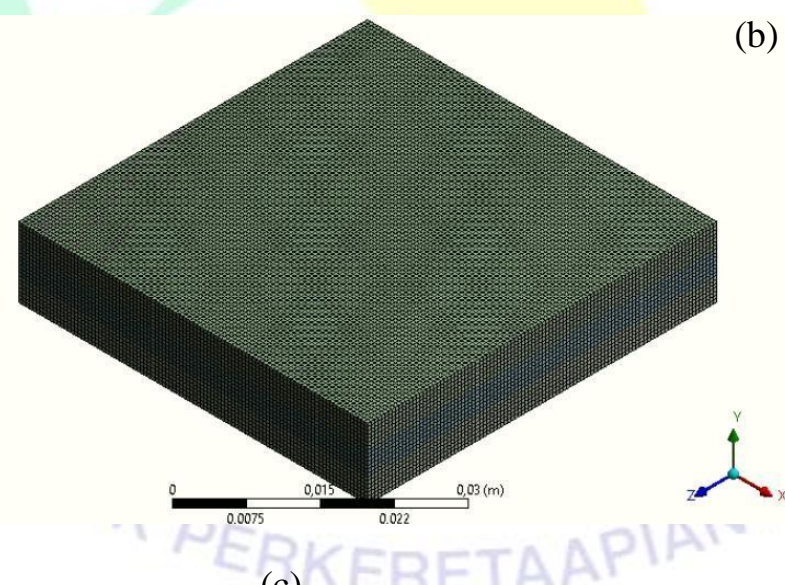

(c) tidak melebihi ukuran minimum yang ditentukan, dalam hal ini $0,5 \mathrm{~mm}$, sehingga hasil yang akurat dapat diperoleh, dan (2) mesh hexahedral: untuk menghasilkan hexahedral, yang merupakan tipe mesh paling ringkas dalam hal efisiensi dan kecepatan komputasi, bahkan mesh heksahedral yang lebih banyak adalah pilihan terbaik untuk mendapatkan resolusi hasil terbaik

Gambar 2 Meshing (a) 1x1 (b) 3x3 (c) 5x5 (cm). 


\section{ANALISIS HASIL}

Permodelan piezoelektrik dilakukan dengan cara memvariasikan ukuran piezoelektrik diantaranya $1 \times 1,3 \times 3$, dan $5 \times 5(\mathrm{~cm})$. Setiap variasi diteliti pada nilai tekanan $0.89,1,26,1,58$ dan $2(\mathrm{~Pa})$.

Tabel 2 Hasil Simulasi Piezoelektrik pada berbagai ukuran.

\begin{tabular}{ccc} 
Ukuran & Tekanan (Pa) & $\begin{array}{c}\text { Tegangan } \\
\text { output }(\mathbf{m V})\end{array}$ \\
\hline $1 \times 1 \mathrm{~cm}$ & 0.89 & 63 \\
\hline & 1.26 & 89 \\
\hline & 1.58 & 111.8 \\
\hline $2 \times 3 \mathrm{~cm}$ & 0.89 & 141.51 \\
\hline & 1.26 & 70 \\
\hline & 1.58 & 99 \\
\hline $5 \times 5 \mathrm{~cm}$ & 2 & 123.82 \\
\hline & 0.89 & 156.74 \\
\hline & 1.26 & 70 \\
\hline & 1.58 & 100 \\
\hline & 2 & 124.91 \\
\hline
\end{tabular}

Tabel 2 menunjukkan nilai tegangan yang dihasilkan oleh piezoelektrik pada variasi ukuran dan variasi nilai tekanan. Pada variasi ukuran piezoelektrik $1 \mathrm{x} 1 \mathrm{~cm}$ tegangan maksimal didapatkan dari variasi tekanan $2 \mathrm{~Pa}$ yaitu sebesar $141.51 \mathrm{mV}$. Pada variasi ukuran $3 \times 3 \mathrm{~cm}$ tegangan maksimal didapatkan pada variasi $2 \mathrm{~Pa}$ yaitu sebesar $156.74 \mathrm{mV}$. Pada variasi ukuran $5 \times 5 \mathrm{~cm}$ tegangan maksimal didapatkan pada variasi $2 \mathrm{~Pa}$ yaitu sebesar $158.12 \mathrm{mV}$.

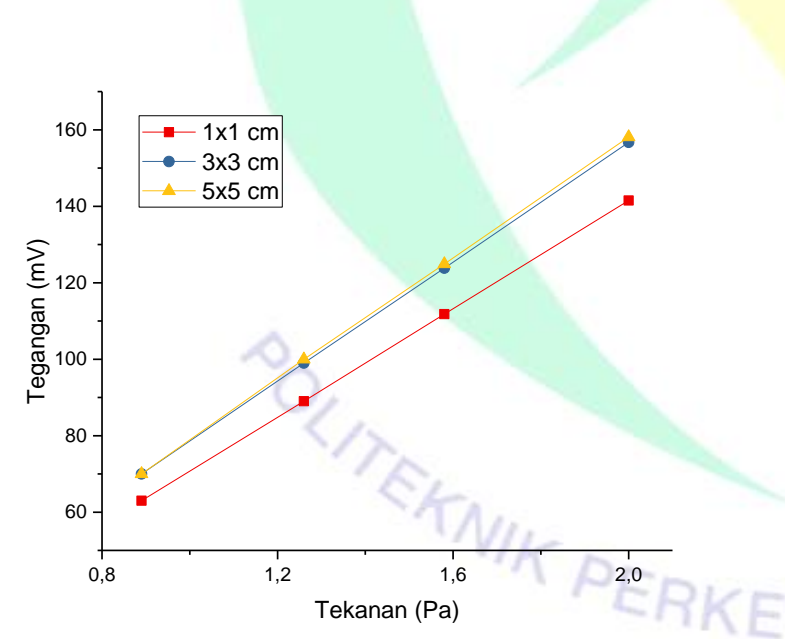

Gambar 3 Hubungan Tekanan dengan Tegangan pada variasi ukuran.

Gambar 3 menunjukkan hubungan antara tekanan dengan tegangan. Grafik tersebut menunjukkan nilai tegangan yang naik seiring dengan kenaikan tekanan dan ukuran piezoelektrik ukuran $1 \times 1(\mathrm{~cm})$ mendapatkan nilai tertinggi pada tekanan 2 Pa yaitu sebesar 141,51 mV. Sedangkan pada tekanan $0.89 \mathrm{~Pa}$ memiliki nilai tegangan yaitu sebesar $63 \mathrm{mV}$. Nilai tegangan pada tekanan 1.26 $\mathrm{Pa}$ dan $1.58 \mathrm{~Pa}$ berturut-turut adalah $89 \mathrm{mV}$ dan $111,8 \mathrm{mV}$. Untuk gambar distribusi tegangan $(\mathrm{mV})$ bisa dilihat pada gambar 4 .

Piezoelektrik dengan ukuran $3 \times 3 \mathrm{~cm}$ mendapatkan nilai tertinggi pada tekana $2 \mathrm{~Pa}$ yaitu sebesar $156,7 \mathrm{mV}$. Sedangkan mendapat tegangan terkecil pada tekanan $0.89 \mathrm{~Pa}$ yaitu sebesar $70 \mathrm{mV}$. Nilai tegangan pada tekanan $1.26 \mathrm{~Pa}$ dan $1.58 \mathrm{~Pa}$ berturut turut adalah $99 \mathrm{mV}$ dan $123.8 \mathrm{mV}$. Piezoelektrik dengan dimensi ukuran $3 \times 3 \mathrm{~cm}$ mengalami kenaikan tegangan rata-rata sebesar $11.18 \%$ jika dibandingkan dengan ukuran $1 \times 1$ $\mathrm{cm}$. Hal ini disebabkan pertambahan dimensi merupakan satu hal yang bisa menyebabkan efek piezo. Untuk gambar distribusi tegangan $(\mathrm{mV})$ bisa dilihat pada gambar 5 .

Piezoelektrik dengan ukuran $5 \times 5 \mathrm{~cm}$ mendapatkan nilai tertingi pada tekanan $2 \mathrm{~Pa}$ yaitu sebesar $158.12 \mathrm{mV}$. Sedangkan mendapat tegangan terkecil pada $0.89 \mathrm{~Pa}$ yaitu sebesar $70 \mathrm{mV}$. Nilai tegangan pada tekanan $1.26 \mathrm{~Pa}$ dan $1.58 \mathrm{~Pa}$ berturut turut adalah $100 \mathrm{mV}$ dan $124.91 \mathrm{mV}$. Piezoelektrik dengan dimensi ukuran $5 \times 5 \mathrm{~cm}$ mengalami kenaikan yang tidak signifikan jika dibandingkan dengan $3 \times 3 \mathrm{~cm}$. Padahal dengan pertambahan dimensi $2 \mathrm{~cm}$, namun mengalami kenaikan yang berbeda jika dibandingkan dengan ukuran piezoelektrik ukuran $3 \times 3 \mathrm{~cm}$ dengan $1 \times 1$ $\mathrm{cm}$. Hal itu terjadi karena efek luasan piezolektrik hampir mengalami tegangan maksimal, sehingga tidak terjadi kenaikan seperti pada ukuran $3 \times 3 \mathrm{~cm}$ . Untuk gambar distribusi tegangan $(\mathrm{mV})$ bisa dilihat pada gambar 6 .

Tegangan output yang dihasilkan oleh piezoelektrik ini terjadi karena efek piezo. Hal itu terjadi karena saat terjadi tegangan $(\mathrm{Pa})$ maka susunan kristal non-centrosmyteric tidak dapat 
mempertahankan posisi atom pusat saat dikenanakan gaya eksternal atau seperti halnya tekanan yang mengenai permukaan piezoelektrik.

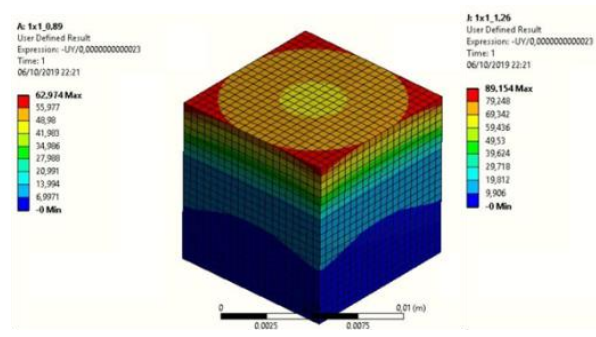

(a)

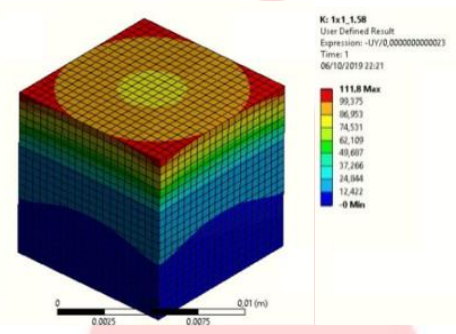

(b)

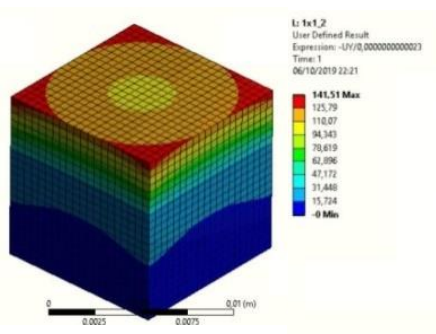

(c)

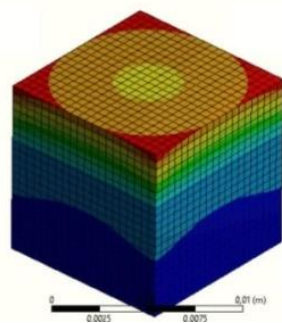

(d)

Gambar 4 Distribusi Tegangan Piezoelektrik Pada Variasi ukuran 1x1 cm (a) $0.89 \mathrm{~Pa}$ (b) 1,26 Pa

(b) $1.58 \mathrm{~Pa}(\mathrm{~d}) 2 \mathrm{~Pa}$
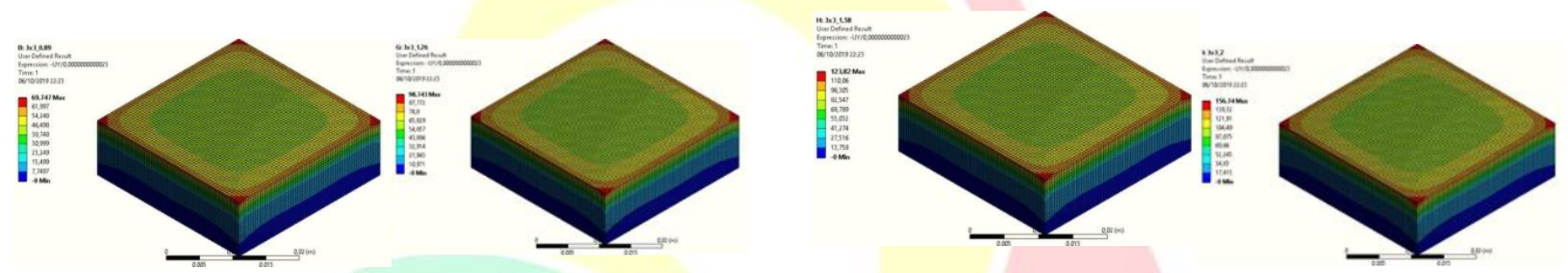

Gambar 5 Distribusi Tegangan Piezoelektrik Pada Variasi ukuran 3x3 cm (a) $0.89 \mathrm{~Pa}$ (b) 1,26 Pa $1.58 \mathrm{~Pa}(\mathrm{~d}) 2 \mathrm{~Pa}$
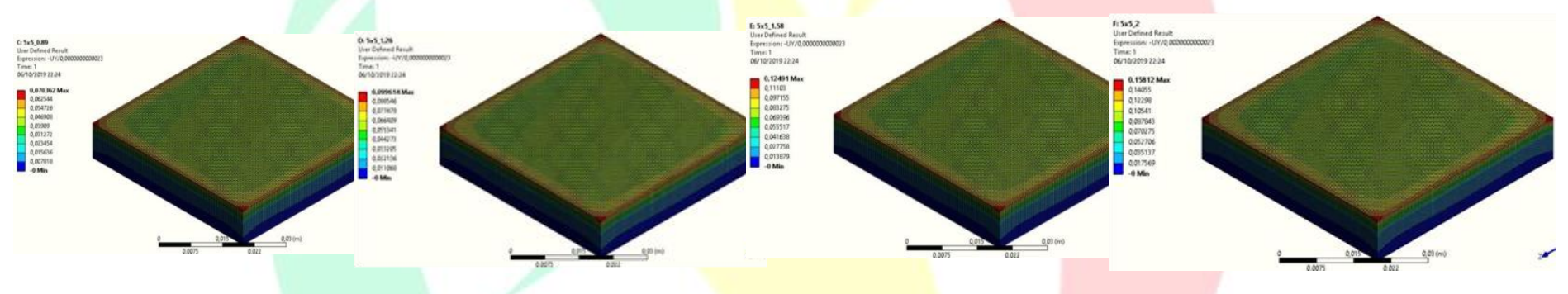

Gambar 6 Distribusi Tegangan Piezoelektrik Pada Variasi ukuran 5x5 cm (a) $0.89 \mathrm{~Pa}$ (b) 1,26 Pa

$$
1.58 \mathrm{~Pa}(\mathrm{~d}) 2 \mathrm{~Pa}
$$

Merujuk hasil simulasi penelitian yang dilakuakan oleh Yuan Wang [5]. Yuan wang meneliti tentang pengaruh kebisingan pada High Speed Train pada piezoelektrik dengan menggunakan Helmholtz resonator terhadap tegangan yang dihasilkan baik secara simulasi dan eksperimen. Hasil yang diperoleh pada penelitian tersebut adalah pada kebisigan $110 \mathrm{~dB}$ piezoelektrik mampu menghasilkan tegangan maksimal sebesar 74.6 $\mathrm{mV}$. Sehingga dari penelitian ini membuktikan bahwa energi bunyi mampu menghasilkan tegangan yang bisa diaplikisan untuk kebutuhan listrik pada kereta

\section{KESIMPULAN}

Berdasarkan hasil simulasi serta analisa data bagimana pengaruh variasi ukuran piezoelektrik serta kebisingan yang dihasilkan oleh kereta dapat diambil beberapa kesimpulan sebagai berikut.

a. Nilai tegangan mengalami kenaikan seiring dengan kenaikan kebisingan dan 
ukuran piezoelektrik. Namun pada penamabahan ukuran piezoelektrik dengan dimensi $5 \times 5 \mathrm{~cm}$ mengalami kenaikan yang tidak signifikan jika dibandingkan dengan $3 \times 3 \mathrm{~cm}$. Ukuran Pirzoelektrik $3 \times 3 \mathrm{~cm}$ mengalami kenaikan $11 \%$ jika dibandingkan dengan ukuran $1 \times 1 \mathrm{~cm}$.

b. Hasil simulasi menunjukkan nilai tegangan maksimal yang dihasilkan pada penelitian ini adalah $158.12 \mathrm{mV}$ pada kebisinga 100 $\mathrm{dB}$ dan ukuran $5 \times 5 \mathrm{~cm}$.

\section{Saran}

Simulasi dengan menggunakan piezoelektrik dengan variasi nilai kebisingan dan ukuran piezoelektrik ini merupakan bahasan penelitian yang cukup menarik, karena voltase yang dihasilkan masih sangat kecil. Penelitian selanjutnya juga dapat dilakukan dengan variasi beberapa material piezoelektrik dan penambahan honeycomb untuk memperbesar tekanan yang mengenai piezoelektrik.

\section{UCAPAN TERIMA KASIH}

Penulis mengucapkan terima kasih kepada p3m PPI Madiun yang telah memberikan hibah penelitian seingga dapat terselesaikannya penelitian ini.

\section{REFERENSI}

K. Riahi, V. Krey, D. McCollum, P. Kolp, and Y. Nagai, "Transport electrification: A key element for energy system transformation and climate stabilization," Clim. Change, vol. 123, no. 3-4, pp. 651-664, 2013.

P. J. Remington and M. J. Rudd, "Measurement and diagnosis of locomotive noise," J. Acoust. Soc. Am., vol. 59, no. S1, pp. S80-S81, 2005.
Y. Yuan, B. Du, Y. Rasim, X. Zhang, C. Wang, and Z. Zhang, "Design, modelling and practical tests on a high-voltage kinetic energy harvesting (EH) system for a renewable road tunnel based on linear alternators," Appl. Energy, vol. 164, no. October 2015, pp. 152-161, 2015.

Z. Zhang et al., "A high-efficiency energy regenerative shock absorber using supercapacitors for renewable energy applications in range extended electric vehicle," Appl. Energy, vol. 178, pp. 177188, 2016.

Y. Wang et al., "A renewable low-frequency acoustic energy harvesting noise barrier for high-speed railways using a Helmholtz resonator and a PVDF film," Appl. Energy, vol. 230, no. July, pp. 52-61, 2018.

X. Zhang, Z. Zhang, H. Pan, W. Salman, Y. Yuan, and Y. Liu, "A portable high-efficiency electromagnetic energy harvesting system using supercapacitors for renewable energy applications in railroads," Energy Convers. Manag., vol. 118, pp. 287-294, 2016.

M. Guan and W. H. Liao, "Design and analysis of a piezoelectric energy harvester for rotational motion system," Energy Convers. Manag., vol. 111, pp. 239-244, 2016.

B. Li, A. J. Laviage, J. H. You, and Y. J. Kim, "Harvesting low-frequency acoustic energy using multiple PVDF beam arrays in quarter-wavelength acoustic resonator," Appl. Acoust., vol. 74, no. 11, pp. 1271-1278, 2013.

M. Fayyadl, J. Fisika, and F. Uns, "Sound Level Meter Extech RS-232.” 